\title{
Retinal and Conjunctival Haemorrhage in the Newborn
}

\author{
J. D. BAUM and C. J. BULPITT \\ From The Neonatal Research Unit, Institute of Child Health, Hammersmith Hospital; and \\ The Department of Medicine, Royal Postgraduate Medical School, Hammersmith Hospital, London
}

Baum, J. D., and Bulpitt, C. J. (1970). Archives of Disease in Childhood, 45, 344. Retinal and conjunctival haemorrhage in the newborn. Two hundred and thirty newborn infants were examined for retinal and conjunctival haemorrhages. Retinal photographs were taken in selected cases to record the morphological varieties and the different rates of disappearance of the retinal haemorrhages.

The incidence of retinal and conjunctival haemorrhages was studied in relation to a number of possible aetiological factors. In the case of retinal haemorrhages we did not identify the critical factor or factors that determine their occurrence. Neither cephalic venous congestion, nor a coagulation defect, nor birth asphyxia was associated with retinal haemorrhages. It is likely that they are of multifactorial origin, and it is suggested that blood viscosity may be an important contributory factor.

In contrast, conjunctival haemorrhages occurred in association with multiparity, rapid second stage of labour, Negro race, high Apgar score, and relatively high birthweight, head circumference, and gestational age. In addition the occurrence of conjunctival haemorrhage as part of the picture of 'traumatic cyanosis' suggests that these lesions do result from changes in cephalic venous pressure.

The first practical ophthalmoscope was introduced by Helmholtz in 1850 . Eleven years later Jaeger first described retinal haemorrhages in newborn infants (Jaeger, 1861). Many studies have since been made concerning the incidence, morphology, aetiology, and significance of these haemorrhages (Richman, 1936; McKeown, 1941; Giles, 1960; Sanchez Ibañez, Belmonte Gonzalez, and Navarro Martinez, 1963; Jain and Gupta, 1965; Schenker and Gombos, 1966; Krauer-Mayer, 1966; Neuweiler and Onwudiwe, 1967). An excellent review is given by Critchley (1968). We have not been able to find any previous study on the incidence and pathogenesis of conjunctival haemorrhages.

We have studied the incidence of retinal and conjunctival haemorrhages in 230 newborn babies in relation to a number of possible aetiological factors. The morphology and rate of disappearance of retinal haemorrhages were examined photographically.

\section{Materials and Methods}

The infants studied were born at Hammersmith Hospital or admitted from elsewhere within a few days of birth. They were examined 15-30 minutes after

Received 11 September 1969. instilling 1 drop of cyclopentolate hydrochloride $0.5 \%$ as a mydriatic. Twice this dose was required in Negro babies.

Healthy infants were wrapped in a blanket and their $\overrightarrow{\bar{O}}$ eyelids were gently held open, care being taken not to 3 press on the orbit. Occasionally a teat was necessary to comfort the infant. On two occasions only, in mature lusty infants, ophthalmoscopy was unsuccessful. Ill infants in the special care baby unit were examined $\frac{2}{\Omega}$ inside their incubators using an indirect ophthalmoscope.

Retinal photographs were taken in selected cases using a vertically mounted Zeiss Fundus Camera (Bulpitt and $\AA$ Baum, 1969). The rate of clearance of retinal blood $\frac{0}{3}$ was estimated by measurement of the haemorrhages on successive photographs when a suitable series was obtained. The transparencies were projected on to a squared paper screen at a fixed distance and the outline을. of the haemorrhage traced. The area was then measured $\mathrm{N}$
by counting squares.

Examination for conjuctival haemorrhages was made $\mathrm{O}$ with the eyelids gently held open. The normal wander-N ing movements of the infant's eyes gave a clear view of $\frac{\omega}{\sigma}$ the sclera. Sometimes it was possible to bring unseen areas of sclera into view by holding the infant vertically, making use of the normal doll's eye phenomenon. क In very small premature infants the sclera was more? difficult to see as the cornea nearly filled the palpebral $\square$ fissure. The sclera was also densely vascular in these $\stackrel{+}{\circ}$ infants, but with practice it was possible to differentiate conjunctival haemorrhage from local scleral injection. 


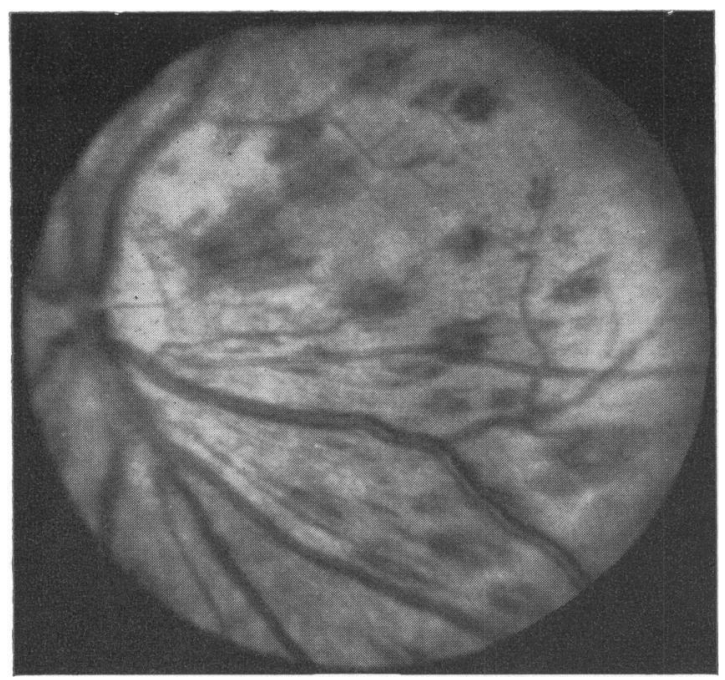

FIG. 1.-Retinal photograph, left eye, showing multiple splinter and small flame haemorrhages, and grossly distended infero-temporal vein.

\section{Results}

Examinations were made on 230 infants at varying times over the first week of life. 20 premature infants were excluded from the analysis because the tunica vasculosa lentis obscured a clear view of the retina, and visualization and interpretation of the scleral appearances were particularly difficult.

Retinal haemorrhages. There are several

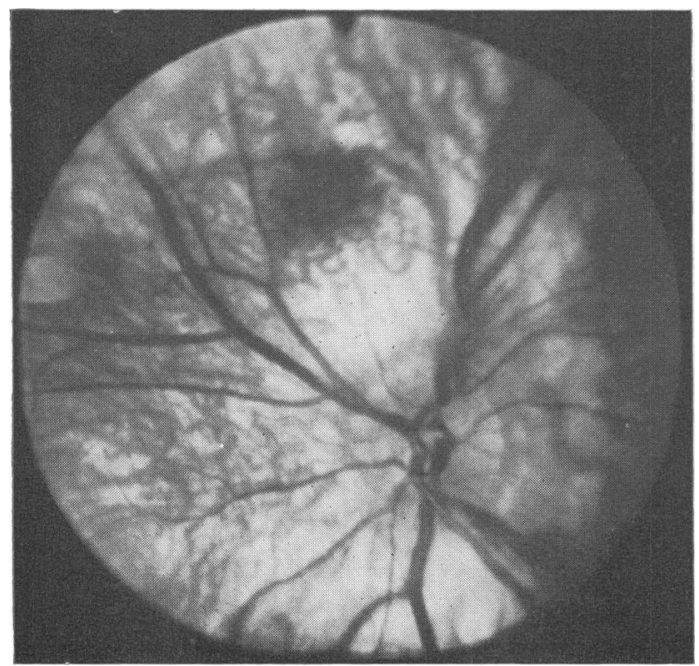

FIG. 3.-Retinal photograph, right eye, showing small lake haemorrhage superior and one disk away from the optic disk; also showing central venous distension.

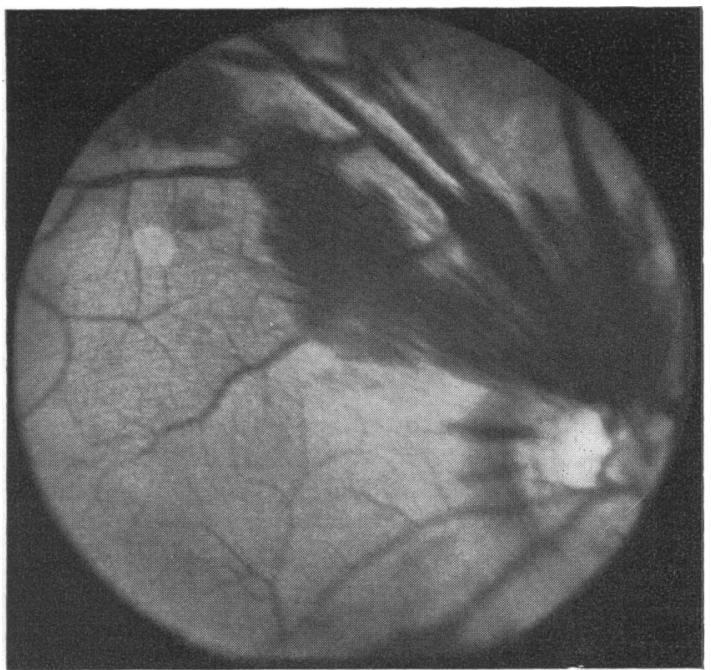

FIG. 2.-Retinal photograph, left eye, showing large flame haemorrhages.

morphological appearances of haemorrhage which are largely a matter of size. Sometimes more than one kind is seen in the same baby.

Splinter haemorrhages (Fig. 1). These are small linear, dull red, and normally lie about the disk margin parallel to the major vessels. They may be single or multiple and they clear very rapidly.

Flame haemorrhages (Fig. 1 and 2). These are the commonest variety. They are bright red, and lozenge-shaped, with a striated or serrated outline.

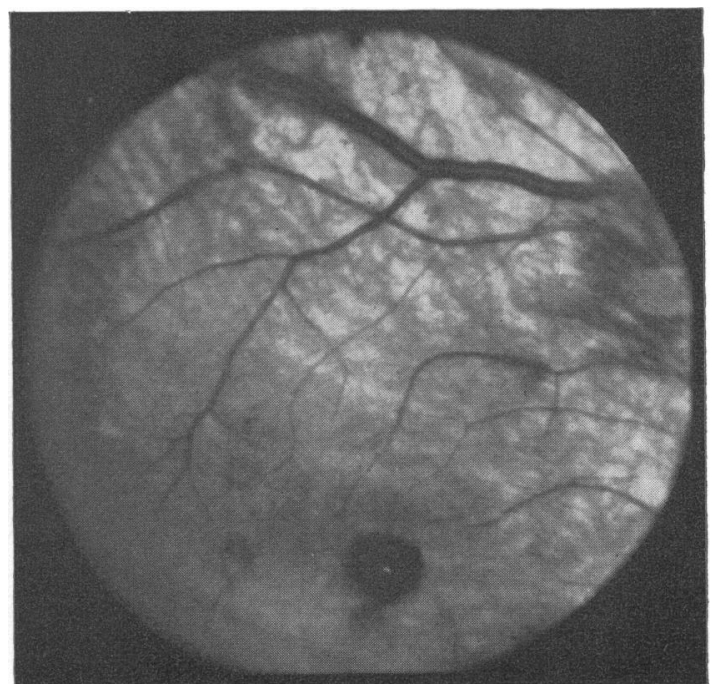

FIG. 4.-Retinal photograph, left eye, showing dense blob haemorrhage at the macula with a central light reflex; also shows gross distension of supero-temporal vein. 
TABLE I

Incidence of Retinal and Conjunctival Haemorrhages at Different Times After Birth

\begin{tabular}{|c|c|c|c|c|c|}
\hline Age at Examination & No. of Babies Seen & $\begin{array}{c}\text { No. With } \\
\text { Retinal } \\
\text { Haemorrhage }\end{array}$ & $\begin{array}{c}\text { \% With } \\
\text { Retinal } \\
\text { Haemorrhage }\end{array}$ & $\begin{array}{l}\text { No. With } \\
\text { Conjunctival } \\
\text { Haemorrhage }\end{array}$ & $\begin{array}{c}\% \text { With } \\
\text { Conjunctival } \\
\text { Haemorrhage }\end{array}$ \\
\hline $\begin{array}{l}0-12 \mathrm{hr} . \\
0-24 \mathrm{hr} . \\
0-48 \mathrm{hr} . \\
0-7 \mathrm{dy} .\end{array}$ & $\begin{array}{r}39 \\
100 \\
152 \\
210\end{array}$ & $\begin{array}{l}12 \\
20 \\
26 \\
33\end{array}$ & $\begin{array}{l}31 \\
20 \\
17 \\
15 \cdot 5\end{array}$ & $\begin{array}{r}2 \\
6 \\
11 \\
29\end{array}$ & $\begin{array}{l}5 \cdot 2 \\
6 \\
7 \cdot 2 \\
13 \cdot 3\end{array}$ \\
\hline
\end{tabular}

They are usually found in the posterior polar region, frequently between the disk and the macula. They may be single or multiple and fade over 3-5 days.

Lake or geographical haemorrhages (Fig. 3). These are less common than the splinter or flame variety. They are bright red, and may cover a large area of retina.

In Negro and Asiatic infants they are clearly seen and appear brown against the pigmented choroid. They clear over 7-9 days.

Dense blob haemorrhages (Fig. 4). These are the least common. They are dense, dark red, and clearly outlined. They occur most frequently in or around the macula. Frequently they show a central light reflex. They are the slowest type of haemorrhage to clear and may persist for 3 weeks or more.

Venous distension (Fig. 1, 3, and 4). Central retinal venous distension commonly accompanies the more extensive haemorrhages.

Incidence. The incidence of retinal haemorrhage in this partly selected population of babies was $31 \%$ in the first 12 hours of life, but $15.5 \%$ when all infants seen within the first week of life were included (Table I).

Thirty-three infants had retinal haemorrhages and these were bilateral in 20 cases. In the 13 unilateral cases the haemorrhages were smaller and less extensive. 10 of the 20 bilateral cases also showed venous distension.

The pattern and rate of clearance of haemorrhages was followed photographically in selected cases. The blood normally disappeared in a centripetal fashion, but occasionally central clearing appeared early. In 8 cases the rate of clearance of the lesions was calculated (Fig. 5).

Analysis of possible aetiological factors. The

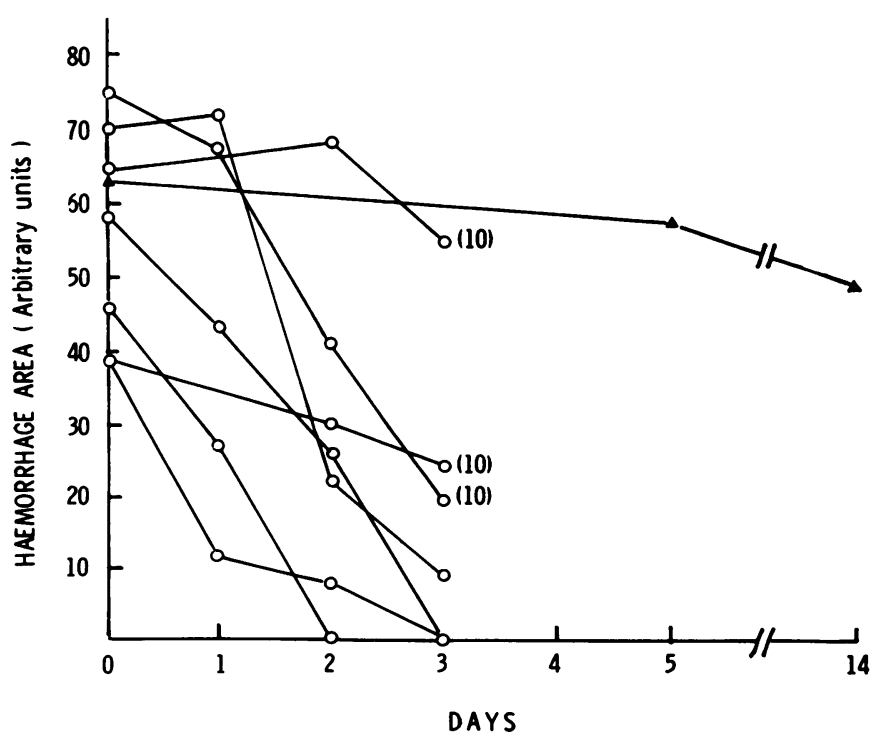

FIG. 5.-The rate of disappearance of retinal haemorrhages. $\Delta=$ dense blob macular haemorrhage, which is very slow to clear. $\mathrm{O}=$ flame haemorrhages of different sizes. $(10)=$ photographs taken on day 10 showed these haemorrhages to have completely disappeared. 
TABLE II

Association of Retinal Haemorrhage with Birth Asphyxia, Expressed as Need for Intermittent Positive Pressure Respiration for More than 5 Minutes After Birth

\begin{tabular}{l|c|c}
\hline & $\begin{array}{c}\text { IPPR } \\
5 \mathrm{~min} .+\end{array}$ & $\begin{array}{c}\text { IPPR } \\
\text { nil or }<5 \mathrm{~min} .\end{array}$ \\
\hline With retinal haemorrhage & 2 & 32 \\
Without retinal haemorrhage & 16 & 128 \\
\hline
\end{tabular}

$\chi^{2}=0 \cdot 82 ; \mathrm{p}=0 \cdot 1-0.5$

incidence of possible aetiological factors was compared in the 33 infants with retinal haemorrhages and the 126 infants who had none when examined within 48 hours after birth.

There was no significant difference in sex distribution, race, birthweight in relation to gestational age, need for positive pressure ventilation during resuscitation (Table II), or mode of delivery (Table III), between the two groups. There were also no significant differences between the mean values in each group for maternal parity, head circumference, birthweight, gestational age, length of first or second stage of labour, Apgar score at 1 minute, packed cell volume, or clotting factors (Table IV).

No relation was established between retinal haemorrhage and asphyxia. There were 9 infants who were in 'terminal asphyxia' at birth, were white, limp and required external cardiac massage, intravenous bicarbonate, and assisted ventilation for more than 20 minutes. In none of these infants were retinal haemorrhages present.

There were 5 instances of 'traumatic cyanosis' of the face, i.e. cyanosis and petechiae on the face,
TABLE III

Association of Retinal Haemorrhage with Mode of Delivery of Infant

\begin{tabular}{c|c|c|c|c|c}
\hline & Vertex & Breech & Caesarean & Forcep & Vacuum \\
\hline $\begin{array}{c}\text { With retinal } \\
\text { haemorrhage }\end{array}$ & 24 & 1 & 3 & 4 & 1 \\
$\begin{array}{c}\text { Without retinal } \\
\text { haemorrhage }\end{array}$ & 85 & 7 & 20 & 8 & 0 \\
\hline
\end{tabular}

$\chi^{2}=1 \cdot 17$ for Caesarean section; $p=0 \cdot 1-0.5$.

with pink limbs and trunk. In none of these were retinal haemorrhages present. Of 4 infants born with cords round their necks, none had retinal haemorrhages.

There were 15 twin pairs in the series. 3 infants ( 2 first twins and 1 second twin) had retinal haemorrhages. In no pair were both twins affected.

In conclusion, no factor was found to be significantly associated with retinal haemorrhage.

Conjunctival haemorrhages. 29 of the 210 infants studied had conjunctival haemorrhages. The incidence did not change significantly at different times from birth (Table I), and conjunctival haemorrhage was often present in infants at their time of discharge from hospital. The haemorrhages were normally contiguous with the nasal or temporal margin of the cornea.

Analysis of possible aetiological factors. Comparison of the 29 infants with, and the 181 infants without conjunctival haemorrhage showed a significant positive correlation of conjunctival haemorrhage with birthweight, head circumference, gestational age, rapidity of second stage of labour,

TABLE IV

Association of Retinal Haemorrhage with Various Factors

\begin{tabular}{|c|c|c|c|}
\hline Features Studied & $\begin{array}{c}\text { Infants } W \text { ith Retinal } \\
\text { Haemorrhage } \\
\text { Mean value } \pm S D(N)\end{array}$ & $\begin{array}{c}\text { Infants Without Retinal } \\
\text { Haemorrhage } \\
\text { Mean value } \pm S D(N)\end{array}$ & $\mathrm{p}^{\star}$ \\
\hline $\begin{array}{l}\text { Head circumference (cm.) } \\
\text { Birthweight (g.) } \\
\text { Gestational age (wk.) } \\
\text { Labour 1st stage (hr.) } \\
\text { Labour 2nd stage (min.) } \\
\text { Apgar at } 1 \text { min. } \\
\text { Parity of mother } \\
\text { Infants' PCV } \\
\text { Platelet count } \times 10^{3} \\
\text { Fibrinogen (mg./100 ml.) } \\
\text { Thrombotest }\end{array}$ & $\begin{array}{c}32 \cdot 1 \pm 2 \cdot 1(33) \\
2468 \pm 597(33) \\
36 \cdot 9 \pm 2 \cdot 9(33) \\
9 \cdot 9 \text { range } 1-38(30) \\
23 \cdot 6 \text { range } 3-100(27) \\
6 \cdot 2 \pm 2 \cdot 9(32) \\
1 \cdot 3 \text { range } 0-4(33) \\
55 \cdot 4 \pm 11 \cdot 7(22) \\
233 \cdot 8 \pm 92 \cdot 2(5) \\
216 \cdot 4 \pm 31 \cdot 5(5) \\
31 \cdot 4 \pm 10 \cdot 2(5)\end{array}$ & $\begin{array}{c}32 \cdot 6 \pm 2 \cdot 5(116) \\
2625 \pm 808(122) \\
36 \cdot 6 \pm 4 \cdot 6(121) \\
8 \cdot 5 \text { range } 0 \cdot 5-40(83) \\
22 \cdot 0 \text { range } 3-120(81) \\
6 \cdot 8 \pm 3 \cdot 0(113) \\
1 \cdot 1 \text { range } 0-4(116) \\
51 \cdot 0 \pm 11 \cdot 3(65) \\
201 \cdot 8 \pm 62 \cdot 2(17) \\
196 \cdot 4 \pm 65 \cdot 3(14) \\
23 \cdot 7 \pm 10 \cdot 2(12)\end{array}$ & $\begin{array}{l}0 \cdot 348 \\
0 \cdot 297 \\
0 \cdot 713 \\
\text { NS } \\
\text { NS } \\
0 \cdot 250 \\
\text { NS } \\
0 \cdot 126 \\
0 \cdot 375 \\
0 \cdot 525 \\
0 \cdot 180\end{array}$ \\
\hline
\end{tabular}

^p values derived from Student $t$ test. 
TABLE V

Association of Conjunctival Haemorrhage with Various Factors

\begin{tabular}{|c|c|c|c|}
\hline Features Studied & $\begin{array}{c}\text { Infants With Conjunctival } \\
\text { Haemorrhage } \\
\text { Mean Value } \pm \text { SD (N) }\end{array}$ & $\begin{array}{c}\text { Infants Without Conjunctival } \\
\text { Haemorrhage } \\
\text { Mean Value } \pm \text { SD (N) }\end{array}$ & $p^{\star}$ \\
\hline $\begin{array}{l}\text { Head circumference (cm.) } \\
\text { Birthweight (g.) } \\
\text { Gestational age (wk.) } \\
\text { Labour 1st stage (hr.) } \\
\text { Labour } 2 \text { nd stage (min.) } \\
\text { Apgar at } 1 \text { min. } \\
\text { Parity of mother }\end{array}$ & $\begin{array}{c}34 \cdot 7 \pm 1 \cdot 9(27) \\
3291 \pm 616(28) \\
39 \cdot 0 \pm 2 \cdot 3(28) \\
9 \cdot 0 \pm 5 \cdot 7(26) \\
14 \cdot 2 \text { range } 5-55(25) \\
8 \cdot 2 \pm 1 \cdot 8(27) \\
2 \cdot 2 \text { range } 0-4(26)\end{array}$ & $\begin{array}{c}32 \cdot 4 \pm 2 \cdot 4(176) \\
2536 \pm 739(181) \\
36 \cdot 9 \pm 3 \cdot 2(182) \\
8 \cdot 8 \pm 7 \cdot 8(130) \\
22 \cdot 7 \text { range } 3-120(120) \\
6 \cdot 8 \pm 3 \cdot 0(171) \\
1 \cdot 1 \text { range } 0-4(180)\end{array}$ & $\begin{aligned}> & 0.001 \\
> & 0.001 \\
> & 0.001 \\
& 0.892 \\
> & 0.05 \\
& 0.021 \\
> & 0.001\end{aligned}$ \\
\hline
\end{tabular}

${ }^{\star} p$ values derived from Student $t$ test.

Apgar score, and maternal parity (Table V). There was also an association with Negro race (Table VI).

TABLE VI

Association Between Conjunctival Haemorrhage and Negro Race

\begin{tabular}{l|c|c}
\hline & Caucasian & Negro \\
\hline With conjunctival haemorrhage & 17 & 11 \\
Without conjunctival haemorrhage & 135 & 28 \\
\hline
\end{tabular}

$\chi^{2}=7 \cdot 2 ; \mathrm{p}=0 \cdot 001-0 \cdot 01$.

No association was found with sex, mode of delivery, need for positive pressure ventilation during resuscitation, or the duration of the first stage of labour. No haematological data were available on these infants. None of the twins, infants with severe birth asphyxia, nor those born with the cord round the neck had conjunctival haemorrhages. The five infants with 'traumatic cyanosis' of the face all had conjunctival haemorrhages.

\section{Discussion}

The population studied was somewhat selected, as 150 of the 230 were infants from the special care baby unit, 116 of whom weighed less than $2500 \mathrm{~g}$. In the first 12 hours of life the incidence of retinal haemorrhage in this series was $31 \%$. This compares with the reported incidence at 24 hours in unselected populations, which ranges from $12 \%$ (Critchley, 1968) to $46 \%$ (Coburn, 1904). The fall in incidence with age has previously been noted by Giles (1960), Jain and Gupta (1965), and others. The rapid rate of clearance of these lesions reflects their small size (Fig. 5). An idea of dimension may be gained by comparison with the transverse diameter of the optic disk which is about $1.7 \mathrm{~mm}$. in the adult (Kunitomo et al., 1967). Of the different morphological patterns of retinal haemorrhage, the splinter and flame varieties lie of in the nerve-fibre layer. The larger lake or $A$ geographical haemorrhages lie superficially beneath the anterior membrane (McKeown, 1941). All the infants had been nursed in a horizontal position and were examined and photographed in this position. This may account for the absence of the characteristic fluid level of the subhyaloid lesion. The denser blob haemorrhages appear to lie deeper in the retina.

It has been frequently stated that the mode of delivery has an influence on the incidence of retinal haemorrhages, which is low after Caesarean section and high after vacuum extraction (Sanchez Ibañez et al., 1963; Neuweiler and Onwudiwe, 1967; Krebs and Jäger, 1966). However, in assessing the significance of retinal haemorrhage after abnormal delivery one must bear in mind the high incidence after entirely normal parturition, and the importance of specifying the exact time after birth when the retinae were examined. In the present series no significant association was found between retinal haemorrhage and the mode of delivery.

It has been suggested that the normal passage through the birth canal leads to increased cephalic venous pressure which may rupture the retinal vessels. There were 5 infants in the present series with 'traumatic cyanosis' of the face. This appearance is believed to result from tight pressure of the cervix around the infants' thorax leading to obstructed drainage from the valveless veins to the head and neck. In none of these five infants were retinal haemorrhages present. It seems, therefore, most unlikely that raised venous pressure is the main factor responsible for rupture of the retinal vessels.

Maumenee, Hellman, and Shettles (1941) showed that giving vitamin $\mathrm{K}$ to mothers 4 days before delivery significantly reduced the incidence of retinal haemorrhage. In the present series coagu- 
lation studies were done in 5 infants with retinal haemorrhages and were found to be normal.

No previous investigators have measured packed cell volume in relation to retinal haemorrhage, but some of the retinal lesions, especially those associated with central retinal venous distension, strongly resembled the adult retinal appearance in polycythaemia. No significant association between PCV and retinal haemorrhage was established in this series. However, the data on PCV were collected retrospectively from samples taken at varying times over the first 2 days after birth.

PCV is related to blood viscosity which rises steeply above a PCV of $60 \%$ (T. Mackintosh, 1969, personal communication). It is suggested that a prospective study of retinal haemorrhage, PCV, and blood viscosity might show a significant positive correlation.

None of the infants with retinal haemorrhages had any evidence of associated intracranial bleeding. Moreover retinal haemorrhage in the newborn is sufficiently common, to make it most unlikely that it usually indicated injury to the central nervous system. However, in view of the well-known association between subarachnoid and subhyaloid haemorrhage after head injury it is likely that infants with major intracranial bleeding after birth may have retinal haemorrhages as well (Hollenhorst and Stein, 1958).

The frequency of retinal haemorrhage also makes it unlikely that it leads to impairment of vision. Follow-up studies have reported normal visual development (Jacobs, 1928; Rowland, 1935; Bonamour, 1949).

In this somewhat selected group of infants the incidence of conjunctival haemorrhage was $13.3 \%$ in the first week of life. When the 80 unselected infants on the postnatal wards were considered alone, the incidence was $31 \%$. Conjunctival haemorrhage was significantly associated with multiparity of mother, rapidity of the second stage of labour, Negro race, greater birthweight, head circumference, and gestational age, and a higher Apgar score. Haemorrhagic disease of the newborn and large sub-aponeurotic haematomas are commoner in Negro babies (Robinson and Rossiter, 1968). However, no data on coagulation factors were available for infants with conjunctival haemorrhages.

Conjunctival haemorrhages were present in all the five infants with traumatic facial cyanosis. In only two instances were retinal and conjunctival haemorrhages present in the same patient. This degree of overlap might be expected on a chance basis from the incidence of the two lesions.
We wish to thank Professor C. T. Dollery and Professor J. P. M. Tizard for their advice and encouragement with this work; Dr. R. J. Robinson for his help with the statistics; Sister Castle and her staff on the Neonatal Unit for their kind co-operation; Dr. Judith Chessells for her assistance with the haematological studies; and the Sir William Coxen Trust for laboratory facilities provided.

This work was supported by the Percy J. Neate Research Fellowship of the Clothworkers Company (J.D.B.) and grants from the Medical Research Council and Tobacco Research Council.

\section{REFERENCES}

Bonamour, G. (1949). Le prognostic éloigne des hémorragies rétiniennes du nouveau-né. Bulletins et Mémoires de la Société Francaise d'Ophtalmologie, 62, 227.

Bulpitt, C. J., and Baum, J. D. (1969). Retinal photography in the newborn. Archives of Disease in Childhood, 44, 499.

Coburn, E. B. (1904). Hemorrhages in the eye, present at birth Archives of Ophthalmology, 33, 256.

Critchley, E. M. R. (1968). Observations on retinal haemorrhages in the newborn. Fournal of Neurology, Neurosurgery and Psychiatry, 31, 259.

Giles, C. L. (1960). Retinal hemorrhages in the newborn. American Fournal of Ophthalmology, 49, 1005.

Hollenhorst, R. W., and Stein, H. A. (1958). Ocular signs and prognosis in subdural and subarachnoid bleeding in young children. Archives of Ophthalmology, 60, 187.

Jacobs, M. W. (1928). The frequency in the newborn of intraocular hemorrhages and their relationship to intracranial trauma. Transactions of the American Academy of Ophthalmology, 33, 218.

Jaeger, E. (1861). Ueber die Einstellung des dioptrischen Apparates im menschlichen Auge. L. W. Seidel, Vienna. Quoted by Giles (1960) q.v.

Jain, I. S., and Gupta, A. N. (1965). Retinal haemorrhages in the newborn. Oriental Archives of Ophthalmology, 3, 121.

Krauer-Mayer, B. (1966). Sur les hémorragies rétiniennes du nouveau-né. Gynécologie et Obstétrique, 65, 77.

Krebs, W., and Jäger, G. (1966). Netzhautblutungen bei Neugeborenen und Geburtsverlauf. Klinische Monatsblätter für Augenheilkunde, 148, 483.

Kunitomo, N., Takeda, M., Terada, T., and Ochiai, A. (1967) New method for the measurement of retinal blood calibers. Acta Societatis Ophthalmologicae faponicae, 71, 1640.

McKeown, H. S. (1941). Retinal hemorrhages in the newborn. Archives of Ophthalmology, 26, 25.

Maumenee, A. E., Hellman, L. M, and Shettles, L. B. (1941). Factors influencing plasma prothrombin in the newborn infant. The effect of antenatal administration of vitamin $K$ on the incidence of retinal hemorrhage in the newborn. Bulletin of the fohns Hopkins Hospital, 68, 158.

Neuweiler, W., and Onwudiwe, E. U. (1967). Retina hămorrhagien beim Neugeborenen. Gynaecologia, 163, 27.

Richman, F. (1936). Retinal haemorrhages in the newborn. Proceedings of the Royal Society of Medicine, 30, 277.

Robinson, R. J., and Rossiter, M. A. (1968). Massive subaponeurotic haemorrhage in babies of African origin. Archives of Disease in Childhood, 43, 684.

Rowland, W. D. (1935). Ocular pathology of the newborn: an end-results study. American fournal of Ophthalmology, 18, 647.

Sanchez Ibañez, J. M., Belmonte Gonzalez, N., and Navarro Martinez, A. (1963). Retina-hämorrhagien beim Neugeborenen nach Vakuum-Extraktion. Gynaecologia, 156, 172.

Schenker, J. G., and Gombos, G. M. (1966). Retinal hemorrhage in the newborn. Obstetrics and Gynecology, 27, 521.

Correspondence to Dr. J. D. Baum, Department of Child Health, Hammersmith Hospital, Du Cane Road, London W.12. 